\title{
Effect of elastane linear density on compression pressure of V-shaped compression socks
}

DOI: 10.35530/IT.069.02.1433

SIDDIQUE HAFIZ FAISAL MAZARI ADNAN

HAVELKA ANTONIN HUSSAIN TANVEER

\section{REZUMAT - ABSTRACT}

\section{Efectul densităţii liniare a elastanului asupra presiunii de compresie a şosetelor de compresie cu fire de vanisare}

Scopul acestui studiu a fost de a evalua efectul densităţii liniare a materialelor din elastan asupra valorilor de compresie laterale (gleznă şi gambă) a unor noi variante de şosete de compresie (cu fire de vanisare). În acest scop, au fost utilizate trei tipuri de fire: fire de bază (MY), fire de vanisare (PY) şi fire de căpuşeală (IY). Fiecare fir conţine material elastan drept miez cu densităţi liniare variabile. Reglajele maşinii au fost optimizate pentru a se obţine şosete de compresie speciale cu fire de vanisare, în funcţie de dimensiunea fixă a piciorului. Toate firele au fost instalate simultan şi evaluate pentru impactul lor asupra valorii presiunii de compresie la diferite segmente de picior. În total, au fost dezvoltate şi cuantificate 18 probe de şosete pentru exercitarea presiunii utilizând dispozitivul MST MKIV, un dispozitiv de monitorizare a presiunii Salzmann. Toate probele au fost analizate utilizând software-ul ANOVA în MINTAB 16. În final, numai două probe de şosete au fost finalizate, obţinându-se valori de exercitare a presiunii de $21 \mathrm{mmHg}$ şi $23 \mathrm{mmHg}$, cu un nivel de compresie graduală de $76 \%$ şi $74 \%$, simultan.

Cuvinte-cheie: compresie, densitate lineară, elastan, şosete cu fire de vanisare, fir filat cu miez, fir acoperit, fir dublu acoperit

\section{Effect of elastane linear density on compression pressure of V-shaped compression socks}

The aim of this study was to evaluate the effect of elastane material linear densities on lateral compression values (ankle and calf) in newly designed shape (V-shape) compression socks. For this purpose, three types of yarns: main yarn (MY), plating yarn (PY) and inlaid yarn (IY) were used. Each yarn contains elastane material as core with varying linear densities. Firstly, Machine adjustments were optimized to achieve special V-shaped compression socks according to fix leg size. All the yarns were installed simultaneously and evaluated for their impact on compression pressure value at different segments of leg. Total eighteen socks samples were developed and quantified for pressure exertion using MST MKIV, Salzmann pressure monitoring device. All samples were analyzed using ANOVA in MINTAB 16 software. Consequently, only two socks samples finalized acquiring pressure exertion values of $21 \mathrm{mmHg}$ and $23 \mathrm{mmHg}$ with graduation percentage of $76 \%$ and $74 \%$ simultaneously.

Keywords: compression, linear density, elastane, V-shaped socks, core spun yarn, air covered yarn, double covered yarn

\section{INTRODUCTION}

Compression socks are highly recommended textile garment for pressure exertion on the lower part of leg [1]. Mechanism of action is a varying degree of compression to different segments of the leg, with the highest pressure at the ankle, must gradually decrease in upward direction. These types of socks are highly recommended for treatment of chronic venous diseased patients [2]. Physical and constructional properties of compression socks are of most importance because its properties directly relate to the type of patient and intensity of the disease. The extent of compression that a patient can easily manage depends on stage (limb size and shape) of venous disease and his activities (mobility, age). Apart from above considerations, compression socks must exert maximum pressure at the ankle, which should decrease to the upper part of the limb. These compression socks must acquire both comfortable and appropriate level of compression. Medical compression devices (MCD) are considered being more effective in preventing and reducing edema if it is capable to exert interface pressure on the gaiter area up to $40 \mathrm{mmHg}$ [3].

As per international classification of pressure exertion intensity, it is classified as CCL1 (light) up to $20 \mathrm{~mm} \mathrm{Hg}$; CCLII (moderate) $20-30 \mathrm{mmHg}$ and CCLIII firm compression $(30-40 \mathrm{mmHg})$. These levels of pressure exertion are recommended medically to treat circulatory and vascular medical conditions as well for tired, sore, swollen, or aching legs [3-6].

Theoretically, the amount of pressure in the circumferential direction of leg depends on the radius $(R)$ of leg and reversal force $T(\mathrm{~N})$.

According to Laplace's Law [5]

$$
P(\mathrm{~Pa})=\frac{T(\mathrm{~N})}{R(\mathrm{~cm})}
$$


Where $P=$ Pressure, $T=$ Reversal fabric tension, $R=$ Radius of leg.

For the pressure measurement on a patient's leg, circumference of the ankle and calf portion is required (1), so the equation (1) can be modified to

$$
P(\mathrm{~Pa})=\frac{T(\mathrm{~N}) \times 2 \pi}{C(\mathrm{~cm})}
$$

Where $P=$ Pressure, $T=$ Reversal fabric tension, $C=$ Circumference of leg

or

$$
P(\mathrm{~Pa})=\frac{T(\mathrm{~N}) \times 2}{W(\mathrm{~cm})}
$$

Where $P=$ Pressure, $T=$ Reversal fabric tension, $W=$ width of socks.

Using the Laplace's formula, it is evident that the operating pressure should be greatest at the point of the lowest girth area (ankle) and have the slightest pressure at the point of maximum girth area (calf). Apart from the position of the leg, the circumference (thin or thick) of the leg also needs optimum or lower pressure on cutaneous and subcutaneous skin layers which satisfies the Laplace's Law [7].

Hui and $\mathrm{Ng}$ (2001) attempted to design a theoretical model for prediction of interface pressure between the skin and garment using multilayer fabric tubes. All tubes have different tensile properties and compare its validation. Designed model is given below.

$$
P=\frac{\in 2 \pi(E 1 h 1+E 2 h 2)}{C}
$$

Where = axial strain, $E=$ modulus of elasticity, $h=$ thickness of textile tube.

This model was experimentally verified by measuring the tensile properties of elastic fabric exhibit breaking load capacity up to $60 \mathrm{~kg}$ and breaking extension capacity in both directions (warp and weft)up to $360 \%$ using an Instron tensile strength machine (model 1026) under zero load, using the cut-strip test. Specimen size selected $5 \times 15 \mathrm{~cm}$, gauge length 10 $\mathrm{cm}$, specimen extended $5-60 \%$ lengthways at $5 \%$ intervals, extended rate $200 \mathrm{~mm} / \mathrm{min}$; clamp width 5 $\mathrm{cm}$ (flat faces), tension load cell was $5 \mathrm{Kg}$. The tension force (Kgf) was recorded for each $10 \%$ stretch to calculate the stress $\left(\mathrm{N} / \mathrm{m}^{2}\right)$ of a fabric specimen. In order to obtain a stable stress-strain curve for an elastic fabric, we ran a few cycles of extension and relaxation before the test. Elastic tubes pressure was measured using oxford MKII pressure monitoring device at fix locations of cylindrical tubes under the elastic fabric. This pressure values were compared with the modulus properties were measured under ASTM D2256-97.Theoretical and actual measurements were compared and found the values to be very closer [8].

Hui and $\mathrm{Ng}$ (2001) attempted to design pressure model for the human leg interface pressure by the compression garment given below. They selected warp knitted elastic fabric and compared these pressure values using Oxford MKII pressure monitoring device between human body skin and donned garment

$$
\mathrm{Re}=\frac{1}{1+\frac{2 \pi \mathrm{El}(\mathrm{CF})}{\text { Chuman }+\mathrm{F}}}
$$

They concluded that compression factor is very important parameter. Instead of using a trial and error approach, this proposed pressure model could help therapists to make pressure garments more effectively and efficiently [9].

Normally, compression socks are recommended for the patients who have stabilized leg circumference and no longer edema. In this situation the socks will correspond effectively to a minor increase in leg circumference. It is also recommended for optimal compression, these would be donned early in the morning when edema is reduced.

A few of the studies are there in which proper development of socks has been done, but mostly researcher had worked on manufactured socks.

Liu et al. (2005) investigated the effect of different material properties and fabric structure characteristics of graduated compression stockings (GCS) on the Skin Pressure Distributions. For this study, they selected eight different commercially available stockings comprised of polyamide and elastane material of varying composition. They concluded that structural characteristics and material properties of stockings were not even along the length of the leg except gradual variation of compression pressure from ankle to thigh which significantly influenced the corresponding skin pressure gradient distributions [10].

Partsch et al. (2006) studied interface pressure and stiffness of ready-made compression stockings. In this study the interface pressure of several medical compression stockings was measured on 12 legs from six employees (5 women, 1 man) having their mean ages 43.2 years (range, 20 to 61 ). Calf-length compression stockings of the European classes I, II, III and the two class I socks over each other were applied on 12 legs. Interface pressure was measured using MST tester using wooden leg models. It was concluded that in vivo and in vitro measurement, an increase in stiffness causes the increase in compression pressure. The highest values are found for two class I stockings applied over each other [8].

Gaieda et al. (2006) used the combination of main yarn as well as inlaid yarn having Lycra in core wrapped by polyamide. The objective was to obtain compression pressure up to $30 \mathrm{~mm}$ of $\mathrm{Hg}$, but observed no significant results except $20 \mathrm{~mm}$ of $\mathrm{Hg}$ was achieved [11].

Maleki et al. (2011) investigated the effect of different stitch lengths $(0.22 \mathrm{~cm}, 0.25 \mathrm{~cm}, 0.27 \mathrm{~cm}, 0.29 \mathrm{~cm}$ and $0.32 \mathrm{~cm}$ ) and repeated usages on two different types (plain and interlock) of knitted structures. They concluded that stitch length is significant parameter, as it increases; there occurs a decrease in pressure and vice versa. While interlock structured fabrics exhibit higher stitch length so display more pressure reduction [12].

Dalbey et al. (2011) had patented their work using core spun yarn having sheath of Polyester as a main 
yarn and double covered Nylon yarn on Lycra core as inlaid yarn achieved maximum compression up to $40 \mathrm{~mm}$ of $\mathrm{Hg}$ [13].

Troynikova O et al. (2013) studied the influence of material properties and garment composition on the pressure generated by sport compression garments using two differently structured knitted fabrics with different physical properties and elastic performance. These samples were tested using compression pressure measuring device MST MK IV. The researchers concluded that different material composition of fabric assemblies influenced the pressure delivery of garment [14].

Normally, socks (weft knitted) are composed of three yarns types defined body yarn, plated yarn and inlaid yarn. Body yarns as in direct contact with skin provide different feels to wearer. Inlaid yarns used are single covered or double covered yarns that run through the heads of loop form by body yarn. It controls stretch, optimum pressure, intimate contact and grip over the leg portion and avoids the sliding of the socks. The loop-forming yarns like body yarn (spun/ filament) and plated yarn (air covered) form the loops together. Inlaid yarn (double covered yarn) is integrated into each loop of every course [13-16].

Various studies exits in which different fiber/yarn types (varying elastane linear densities and compositions) different types of spun/core spun yarns of different linear densities, different kind of inlaid yarn, varying tension by increasing or decreasing ultra feeder yarn tensions into knitting machine and different fabric structures (manufactured and ready-made), different sizes and shapes of the substrate (cylindrical tube or wooden leg) had been used to exert maximum pressure at the ankle and optimum graduation $[2,4,14,16-18]$. But there is no study in which the effect elastane material linear densities used in all the three socks components body yarn, plated yarn and inlaid yarn is studied in specially designed V-shaped socks.

In normal compression socks graduation percentage varies from $60 \%$ to $80 \%$ of the total compression pressure at the ankle. The most important property required in graduated compression socks is to attain the highest sub-garment compression pressure at ankle according to European classification of compression pressure. The graduation compression pressure means

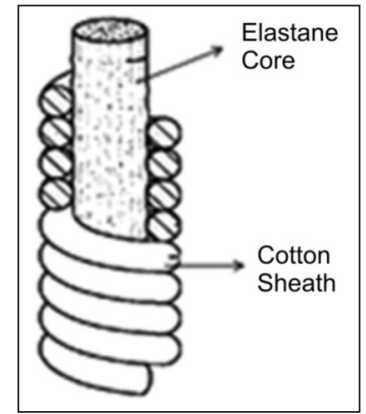

Fig. 1. Front view of Core Spun yarn [12] gradually lowering of pressure along the length of the leg towards the calf. If does not reduces while moving upward may cause blood clotting and swelling of inner walls of the veins. The intensity of compression pressure suggested for the patients depends on the type, history and intensity of the disease. The severe is the disease, the higher compression pressure suggested for the patient to prevent the recurrence of lymph edema.

The objective of this study is to investigate the influence main yarn (MY), plating yarn (PY), and inlaid yarn (IY) on compression pressure at ankle, calf and graduation percentage between 70 to $80 \%$.

\section{MATERIALS AND METHOD}

\section{Materials (yarns)}

Compression socks are comprised of three yarns types i.e. main, plated and inlaid abbreviated as main yarn (MY), plating yarn (PY) and Inlaid yarn (IY).

Main/Body yarn: Three types of main yarns (core Spun) were selected abbreviated as (MY1* ${ }^{*} \mathrm{MY}^{*}$ \& $\mathrm{MY}^{*}$ ) as shown figure 1 . All have same Overall linear density i.e. 29.52 tex but different elastane material linear densities i.e. 4.4 tex, 7.77 tex, 11.7 tex respectively. Here *MY1: 4.4 tex Lycra-29.52/1 tex core spun cotton 96\%, *MY2: 7.8 tex Lycra-29.52/ 1 tex core spun cotton 93\% and ${ }^{*} \mathrm{MY} 3$ : 11.7 tex Lycra-29.52/1 tex core spun cotton 90\%. Testing results of main yarn are given below in table 1 .

Inlaid yarn: Three types of double covered Nylon filament yarn were selected as shown in figure 2 can be abbreviated as $\left(I Y 1^{*}, I Y 2^{*} \& I Y 3^{*}\right)$. Each type contains elastane yarn of different linear densities i.e. 13.3 tex, 15.5 tex and 33 tex but fixed sheath yarn linear density i.e. 15.55 tex/24f/1. Here *IY1: 13.3 tex15.55/ 24f/1 tex Raw White Nylon DCV 17\%, *IY2: 15.50 tex-15.55/24f/1 tex Raw White Nylon DCV 19\% and *IY3: 33.0 tex-15.55/24f/1 tex Raw White

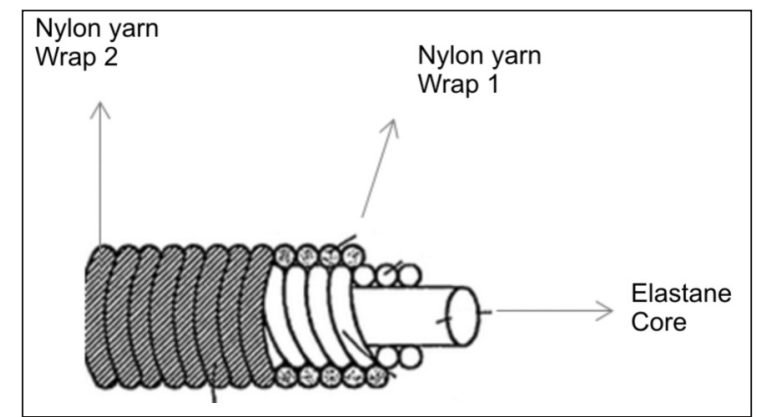

Fig. 2. Double covered Nylon Filament yarn [19]

Table 1

\begin{tabular}{|c|c|c|c|c|c|}
\hline \multirow{2}{*}{ Sr. no } & \multirow{2}{*}{ Main yarn codes } & \multicolumn{2}{|c|}{ Yarn linear density (tex) } & \multirow{2}{*}{ Draw ratio } & \multirow{2}{*}{ Elastane composition (\%) } \\
\cline { 3 - 5 } & & Resultant & Elastane & & \\
\hline 1 & MYELD1 & 29.52 & 4.4 & 3.48 & 4.32 \\
\hline 2 & MYELD2 & 29.52 & 7.8 & 3.64 & 7.22 \\
\hline 3 & MYELD3 & 29.52 & 11.7 & 3.65 & 10.83 \\
\hline
\end{tabular}

MY: Main Yarn, E: Elastane, LD: Linear Density 


\begin{tabular}{|c|c|c|c|c|c|c|}
\hline \multirow{2}{*}{ Sr. no } & \multirow{2}{*}{ Inlaid yarn codes } & \multicolumn{2}{|c|}{ Yarn linear density (tex) } & \multirow{2}{*}{ Draw ratio } & $\begin{array}{c}\text { Elastane composition } \\
\text { (\%) }\end{array}$ \\
\cline { 3 - 6 } & & DCV Resultant & Nylon & Elastane & & 17.27 \\
\hline 1 & IYELD1 & 20.22 & 15.55 & 13.3 & 1.63 & 18.6 \\
\hline 2 & IYELD2 & 21.11 & 15.55 & 15.5 & 1.85 & 34.08 \\
\hline 3 & IYELD3 & 27.33 & 15.55 & 33 & 1.56 & \\
\hline
\end{tabular}

IY: Inlaid Main, E: Elastane, LD: Linear Density

Table 3

\begin{tabular}{|c|c|c|c|c|c|c|}
\hline \multirow{2}{*}{ Sr. no } & \multirow{2}{*}{$\begin{array}{c}\text { Plating yarn } \\
\text { codes }\end{array}$} & \multicolumn{3}{|c|}{ Yarn linear density (tex) } & \multicolumn{2}{c|}{ Elastane } \\
\cline { 3 - 7 } & ACV & Sheath & Elastane & Draw ratio (\%) & Composition (\%) \\
\hline 1 & PYED1 & 9.11 & 7.77 & 2.2 & 3.2 & 8 \\
\hline 2 & PYED2 & 9.44 & 7.77 & 2.2 & 2 & 12.5 \\
\hline
\end{tabular}

PY: Plated Yarn, E: Elastane, D: Draft

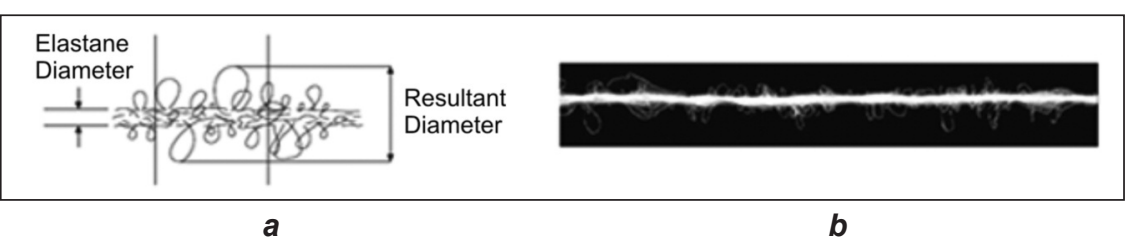

Fig. 3. Side view of ACV yarn:

$a$ - resultant and elastane diameter; $b$ - scanned plated air covered yarn [20] zone, 108 courses were inserted with decreasing degree of needles from the calf portion (400 degree) to ankle portion (100 degree). A zone with the lowest degree (100) of needles was introduced at the ankle portion as required lowest loop height to exert highest pressure and highest degree (400) at calf portion

Nylon DCV 34\% (DCV: Double covered). Testing results of inlaid yarns are given in the table 3 .

Plating yarn: Two types of nylon air covered yarns were selected abbreviated as $\left(P Y 1^{*}\right.$ \& $P Y 2^{*}$ ) as shown in (figure 3$)$ having different draft values $(2 \%$ \& $3.2 \%)$ were selected. Here *PY1: 2.2 tex Lycra7.77 tex/24 filamnet/1 Raw White Nylon ACV 8\%, *PY2: 2.2 tex Lycra-7.77 tex/24 filament/1 Raw White Nylon ACV 12.5\% [ACV: air covered]. Testing results of plating yarn are given in table 2 .

\section{Method}

\section{Machine specifications}

Technical specifications of selected conventional machine are given below in table 4 .

\section{Optimization of machine adjustments}

In this section, we adjusted the conventional socks knitting machine to 2 steps special settings to achieve desired V-shape ribbed socks. Step (I): Gradient change in the Degree of needles for main and plating yarns Step (II): Varying graduation motor speed for Inlaid yarn as shown in figure 4 and figure 5 . Total 322 courses were inserted in the rib portion $(1 \times 1)$ of each socks sample.

Main yarn and plating yarn insertion were divided into three zones of varying degree of needles. In each is required to attain lower pressure at calf than ankle. Inlaid yarn insertion was divided into seven zones and controlled by varying graduation motor speed from $600 \mathrm{rpm}$ to $1400 \mathrm{rpm}$ from calf to ankle. In seven zones, each zone contains 46 courses with reduction of constant speed of $200 \mathrm{rpm}$ of graduation motor at each zone out of seven.

After optimization of machine adjustments, $V$ shape socks were manufactured at above mentioned setting, but with changing types of yarns.

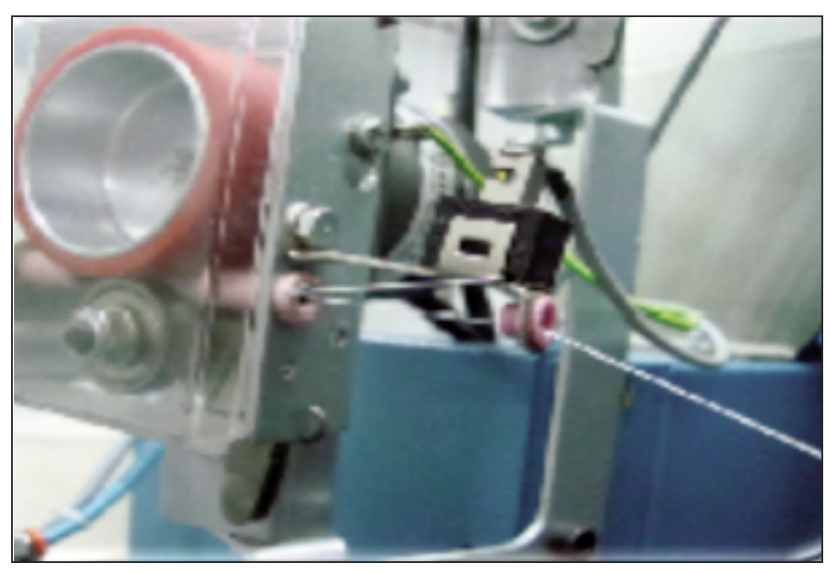

Fig. 4. Schematic diagram of elastic motor

Table 4

\begin{tabular}{|c|c|c|c|c|c|c|c|}
\hline Model & Company & Cylinder & Gauge & Diameter & Speed & Feeder & Needles \\
\hline L462 2005 & Lonati & Single & 12 & $3.75^{\prime \prime}$ & $250 \mathrm{rpm}$ & 2 & 168 \\
\hline
\end{tabular}




\section{Preparation of $\mathbf{V}$ shaped socks}

Three yarns (main, plating and Inlaid) were loaded on socks knitting machine at above mentioned adjustments. Desired V- shape socks are shown in figure 5.

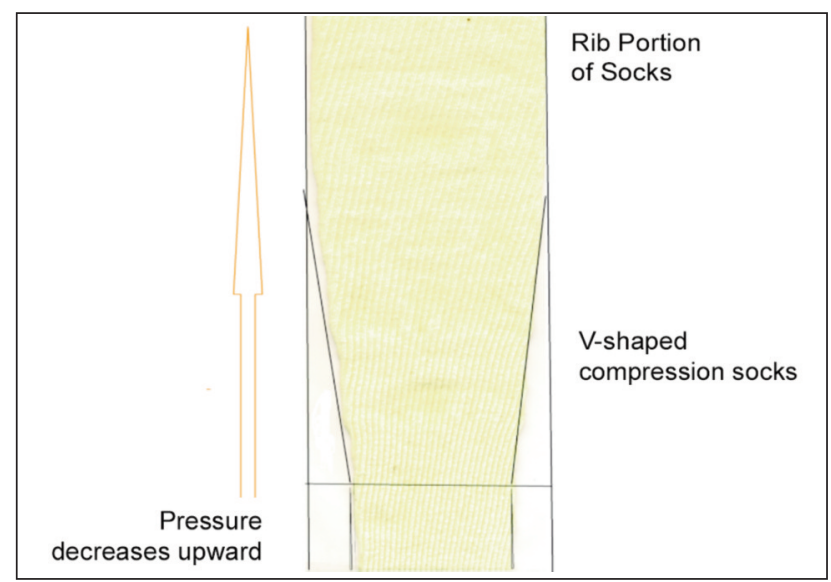

Fig. 5. V-shaped compression socks prepared on conventional knitting machine

\section{Physical specifications of socks samples and wooden leg}

Widths (diameter) of all the socks samples were measured at the ankle $(6.5 \mathrm{~cm}$ to $8.5 \mathrm{~cm})$ and a calf portion $(9 \mathrm{~cm}$ to 10.5). This difference in widths is due to machine adjustments and varying linear densities of elastane materials. Width measurements of the socks samples and wooden leg are given below in table 5 .

Table 5

\begin{tabular}{|c|c|c|c|}
\hline $\begin{array}{c}\text { Sr. } \\
\text { no. }\end{array}$ & $\begin{array}{c}\text { Socks } \\
\text { width }\end{array}$ & $\begin{array}{c}\text { Unit } \\
\text { (cm) }\end{array}$ & $\begin{array}{c}\text { Wooden leg width } \\
\text { (cm) }\end{array}$ \\
\hline 1 & Ankle & $6.5-8.5$ & 8.28 \\
\hline 2 & Calf & $9-10.5$ & 12.42 \\
\hline
\end{tabular}

\section{Pressure measurement of V-shaped socks}

Compression pressure of all the socks samples was measured using MST MK IV SALZMANN compression tester under standard test method of ENV 12718 as shown in figure 6 . The device consists of a thin plastic sleeve ( $4 \mathrm{~cm}$ wide, $0.5 \mathrm{~mm}$ thick), with four to six paired electrical contact points. The measuring points are B, ankle; B1, gaiter area; $\mathrm{C}$, largest calf circumference; and $D$, below knee as shown in figure 6 , connected to an air pump and a pressure transducer. This probe is placed between the leg and the compression device. The air pump at rate of $1 \mathrm{mmHg} / \mathrm{sec}$ inflates the wrapper until the contacts open. The contact of compression garment to wooden leg is diminished when the inner pressure exerted by the air is just above external pressure due to the compression device. When the contact opens, the transducer reads the pressure at each measuring point and the pressure value displayed digitally with $1-\mathrm{mmHg}$ resolution [1].

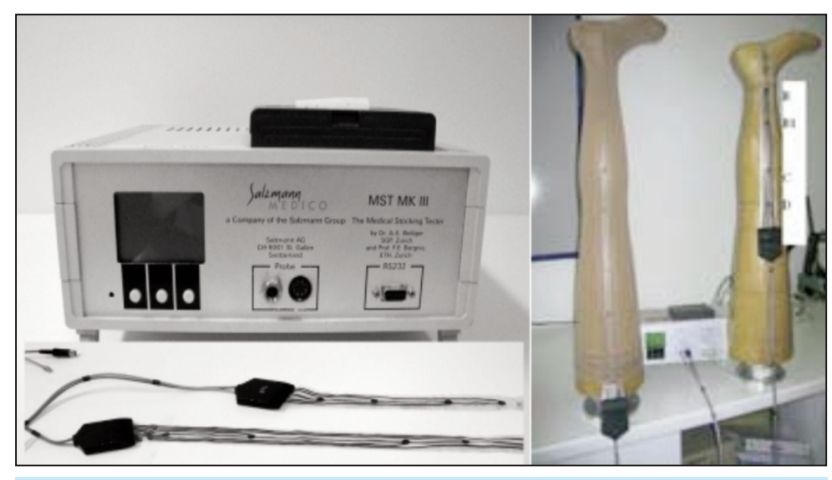

Fig. 6. Schematic diagram of MST MKIV Salzmann pressure-measurement device

Compression pressure values at ankle portion, calf portion and graduation percentage ( $G \%$ ) was calculated. $G \%$ is a very important factor keep in mind as helpful to regulate the blood flow. Liu et al. (2005) studied that the compression socks should exert maximum pressure at ankle decreasing to upward (hip side) [4]. This gradient change in pressure, generate the pressure between capillaries and enhance the rate of blood flow through the veins [1].

Graduation percentage ( $G \%$ ) from ankle to calf portion is calculated using formula

Graduation percentage $(G \%)=\left(P^{c} \div P a\right) \times 100$

$P^{c}=$ Pressure at calf portion, $\mathrm{Pa}=$ Pressure at ankle portion (16).

\section{RESULTS AND DISCUSSION}

\section{Compression properties}

The experimental variables are: main yarn elastane linear density (MYELD), plating yarn elastane draft (PYED) and in-laid yarn elastane linear density (IYELD). Table 6 shows compression pressure values of developed socks at the ankle, at the calf and the percentage graduation.

\section{Effect of elastane linear densities (main and Inlaid) and draft (plated) at ankle}

Effect of elastane linear densities used in all socks samples at the ankle was analyzed first using ANOVA tool (Statistical software MINITAB). In this case to construe whether the parameters are significant or not, $p$ values are examined. As known, if the ' $p$ ' value of a parameter is greater than $0.05(p>0.05)$, the parameter will not be statistically significant. ANOVA values of compression pressure at ankle are shown in table 7.

The analysis of variance data shown in table 4 indicates that the p-value of effect of main yarn elastane linear density (MYELD) and inlaid yarn elastane linear density (IYELD) is below 0.05 which depict the significant influence of input variables on compression pressure at ankle while the impact of plating yarn elastane draft on compression pressure at ankle is non-significant $(p>0.005)$.

Figure 7 and figure 8 portray the trend of main yarn elastane linear density, inlaid yarn elastane linear density and plating yarn elastane draft on exertion pressure at ankle. 
Table 6

\begin{tabular}{|c|c|c|c|c|c|c|c|}
\hline $\begin{array}{l}\text { Sr. } \\
\text { no. }\end{array}$ & $\begin{array}{l}\text { Code } \\
\text { detail }\end{array}$ & $\begin{array}{l}\text { MYELD } \\
\text { [dtex] }\end{array}$ & $\begin{array}{l}\text { IYELD } \\
\text { [dtex] }\end{array}$ & $\begin{array}{l}\text { PYED } \\
\text { [ratio] }\end{array}$ & $\begin{array}{c}\text { Pressure at ankle }\left(P_{a}\right) \\
{[\mathrm{mmHg}]}\end{array}$ & $\begin{array}{c}\text { Pressure at calf }\left(P_{c}\right) \\
{[\mathrm{mmHg}]}\end{array}$ & $\begin{array}{c}\text { Graduation } \\
\text { [\%] }\end{array}$ \\
\hline 1 & M1I1P1 & 44 & 133 & 2 & 13 & 11 & 84.61 \\
\hline 2 & M1I1P2 & 44 & 133 & 3.2 & 15 & 14 & 93.3 \\
\hline 3 & M1I2P1 & 44 & 155 & 2 & 13 & 11 & 84.6 \\
\hline 4 & $\mathrm{M} 1 \mathrm{I} 2 \mathrm{P} 2$ & 44 & 155 & 3.2 & 13 & 14 & 107.69 \\
\hline 5 & M1I3P1 & 44 & 330 & 2 & 21 & 16 & 76.19 \\
\hline 6 & M1I3P2 & 44 & 330 & 3.2 & 23 & 17 & 73.91 \\
\hline 7 & M2I1P1 & 78 & 133 & 2 & 16 & 14 & 87.5 \\
\hline 8 & M2I1P2 & 78 & 133 & 3.2 & 18 & 16 & 88.8 \\
\hline 9 & M2I2P1 & 78 & 155 & 2 & 17 & 15 & 88.23 \\
\hline 10 & M2I2P2 & 78 & 155 & 3.2 & 18 & 17 & 94.44 \\
\hline 11 & M2I3P1 & 78 & 330 & 2 & 26 & 22 & 91.66 \\
\hline 12 & M2I3P2 & 78 & 330 & 3.2 & 24 & 22 & 91.66 \\
\hline 13 & M3I1P1 & 117 & 133 & 2 & 17 & 16 & 94.11 \\
\hline 14 & M3I1P2 & 117 & 133 & 3.2 & 16 & 16 & 100 \\
\hline 15 & M3I2P1 & 117 & 155 & 2 & 19 & 16 & 84.21 \\
\hline 16 & M3I2P2 & 117 & 155 & 3.2 & 17 & 18 & 105.88 \\
\hline 17 & M3I3P1 & 117 & 330 & 2 & 22 & 22 & 100 \\
\hline 18 & M3I3P2 & 117 & 330 & 3.2 & 23 & 22 & 95.65 \\
\hline
\end{tabular}

M1, M2 \& M3 = Main Yarns, I1, I2 \& I3: Inlaid yarns, P1 \& P2 = Plated Yarns

Table 7

\begin{tabular}{|c|c|c|c|c|c|}
\hline Source & DF & Adj. SS & Adj. MS & F-value & P-value \\
\hline Model & 13 & 243.114 & 18.7011 & 24.57 & 0.004 \\
\hline Linear & 5 & 230.112 & 46.0223 & 60.46 & 0.001 \\
\hline MYELD & 2 & 40.148 & 20.0741 & 26.37 & ${ }^{*} 0.005$ \\
\hline ILELD & 2 & 189.561 & 94.7807 & 124.51 & ${ }^{*} 0.000$ \\
\hline PYED & 1 & 0.402 & 0.4020 & 0.53 & 0.508 \\
\hline Error & 4 & 3.045 & 0.7612 & & \\
\hline Total & 17 & 246.159 & & & \\
\hline
\end{tabular}

* Significant variables

Figure 7 and figure 8 demonstrate that as the linear density of the elastane material of the main yarn increases from 44 detx to 78 detx, increase in

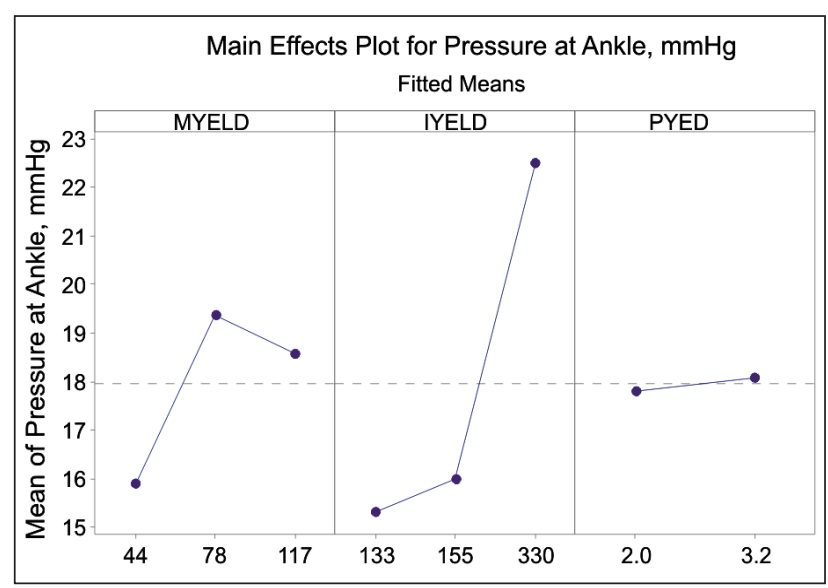

Fig. 7. Main yarn elastane linear density (MYELD), Plating yarn elastane Draft (PYED) and inlaid yarn elastane linear density (IYELD) Vs compression pressure $(\mathrm{mm} \mathrm{Hg})$ at ankle

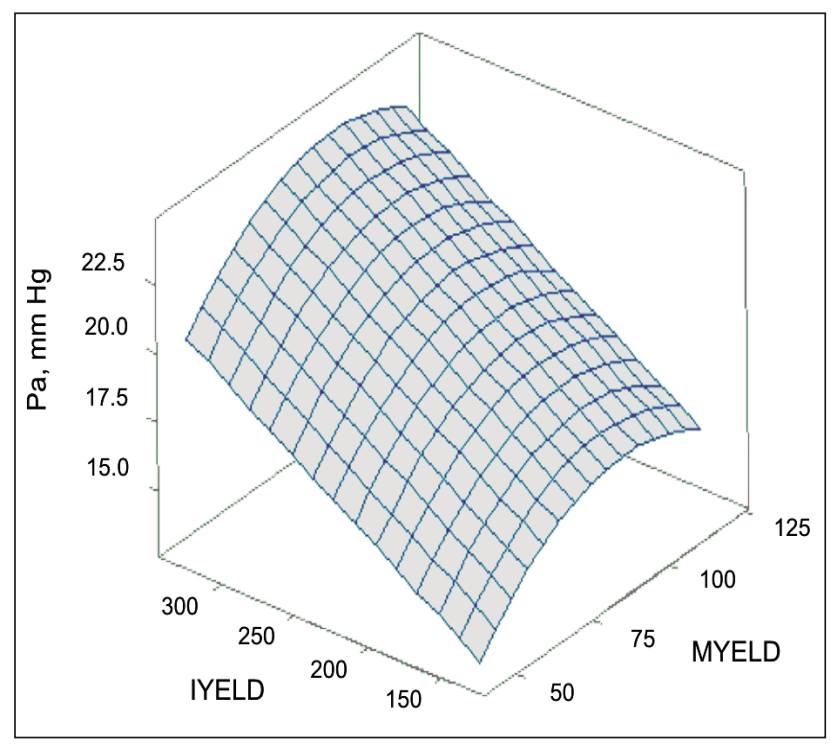

Fig. 8. Surface plot of pressure at ankle $(\mathrm{mm} \mathrm{Hg}) \mathrm{Vs}$ Main yarn elastane linear density (MYELD), and inlaid yarn elastane linear density (IYELD) 
compression pressure from $16 \mathrm{~mm} \mathrm{Hg}$ to $19 \mathrm{~mm} \mathrm{Hg}$ at ankle takes place. But as the linear density of elastane material increases more from 78 detx to 117 dtex, a non-significant decrease in compression pressure at ankle from $19 \mathrm{~mm} \mathrm{Hg}$ to $18 \mathrm{~mm} \mathrm{Hg}$ takes place. Increase in compression pressure from $16 \mathrm{~mm}$ $\mathrm{Hg}$ to $19 \mathrm{~mm} \mathrm{Hg}$ by increasing the linear density of the elastane material is due to increase in the contraction of the socks. The fabric density at ankle increases as the linear density of the elastane material increases, which gradually reduces loop length and air spaces while increasing the stiffness and compactness of the fabric. As the linear density of the main yarn elastane material increases more $78 \mathrm{dtex}$ to $177 \mathrm{dtex}$, there observed a slight decrease in compression pressure. The reason of decrease in compression pressure is due to additional compactness/least air spaces in knitted fabric which do not allow the fabric to contract more than the size of the wooden leg minimum girth area (ankle) ultimately reducing the compression pressure at ankle. The wooden dummy used in this study has width/circumference $(\mathrm{cm}) 8.28 / 26 \mathrm{~cm}$ while the prepared socks has the width range from $6 \mathrm{~cm} \sim 7.5 \mathrm{~cm}$ that when worn to leg size it is stretched to extent according to circumference of the leg.

Inlaid yarn is the yarn which moves transversely along each course of main yarn loops while missing the one loop of the wale (rib construction $1 \times 1$ ). It is evident from the figure 7 and figure 8 that as the linear density of the elastane material increases from 133 dtex to 155 dtex, a slight increase in compression pressure from $15 \mathrm{~mm} \mathrm{Hg}$ to $16 \mathrm{~mm} \mathrm{Hg}$ takes place but as the linear density of the inlaid yarn increases from $155 \mathrm{dtex}$ to $330 \mathrm{dtex}$, incredible increase in compression pressure from $16 \mathrm{~mm} \mathrm{Hg}$ to $23 \mathrm{~mm} \mathrm{Hg}$ takes place.

Diana et al. (2013) reported that the linear pressure depends on the linear density of the PU core material and insertion density of the inlaid yarn. She also reported that extensibility of the socks can be controlled (transversely and longitudinally) by the increasing or decreasing insertion density of the inlaid yarn according to requirement [23].

Pressure at Ankle $(\mathrm{mm} \mathrm{Hg})=2.03+0.3094$ MYELD + +0.03681 IYELD - 0.001693 MYELD * MYELD (7)
R-Sq. for the regression equation (1) is $93 \%$ which signifies that $93 \%$ change in compression pressure at ankle can be explained by the terms included in the equation.

\section{Effect of elastane linear densities (main and inlaid) and draft (plated) at calf}

Analysis of developed compression socks at calf was made using statistical software called as MINITAB. For the statistical importance of the experimental factors, analysis of variance (ANOVA) tool was applied. In order to construe whether the parameters were significant or not, $p$ values were examined. As known, if the ' $p$ ' value of a parameter is greater than $0.05(p>0.05)$, the parameter will not be statistically significant.

The analysis of variance data shown in table 8 indicates that the $p$-value of main yarn elastane linear density (MYELD) and inlaid yarn elastane linear density (IYELD) and plating yarn elastane draft is below 0.05 which depict the significant influence of input variables on the compression pressure at calf.

Figure 9, 10 and 11 represents the impact of main yarn elastane linear density, inlaid yarn elastane linear density and plating yarn elastane draft on the exertion pressure at the calf.

Main yarn is usually in contact with the skin and forms the wales and courses in the socks, which transversely and longitudinally affect the socks size and compactness of loops in knitted fabric. Figures 9,

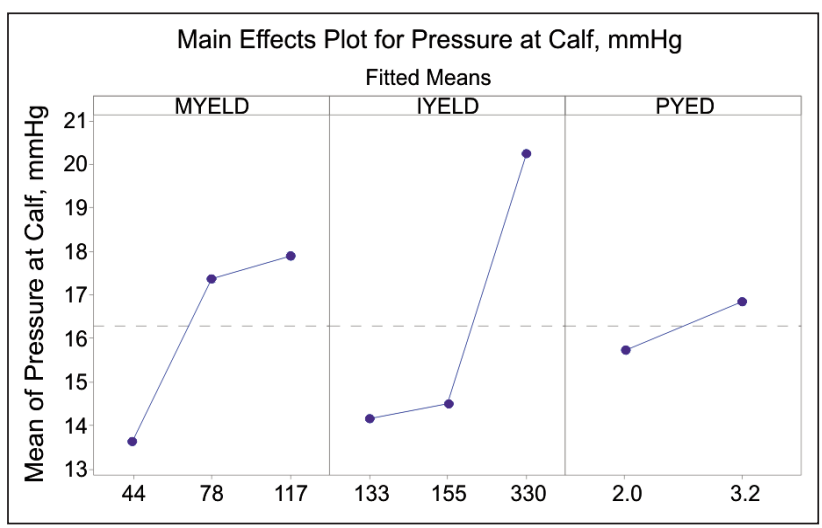

Fig. 9. Main effect plot of main yarn elastane linear density (MYELD), Plating yarn elastane draft (PYED) and inlaid yarn elastane linear density (IYELD) Vs compression pressure $(\mathrm{mm} \mathrm{Hg})$ at calf

\begin{tabular}{|c|c|c|c|c|c|}
\hline Source & DF & Adj. SS & Adj. MS & F-value & P-value \\
\hline Model & 13 & 224.590 & 17.2762 & 25.32 & 0.003 \\
\hline Linear & 5 & 211.697 & 42.3394 & 62.05 & 0.001 \\
\hline MYELD & 2 & 65.091 & 32.5453 & 47.69 & ${ }^{*} 0.002$ \\
\hline ILELD & 2 & 141.006 & 70.5032 & 103.32 & ${ }^{*} 0.000$ \\
\hline PYED & 1 & 5.600 & 5.6001 & 8.21 & ${ }^{*} 0.046$ \\
\hline Error & 4 & 0.6824 & 0.6824 & & \\
\hline Total & 17 & 227.320 & & & \\
\hline
\end{tabular}

*Significant variables 


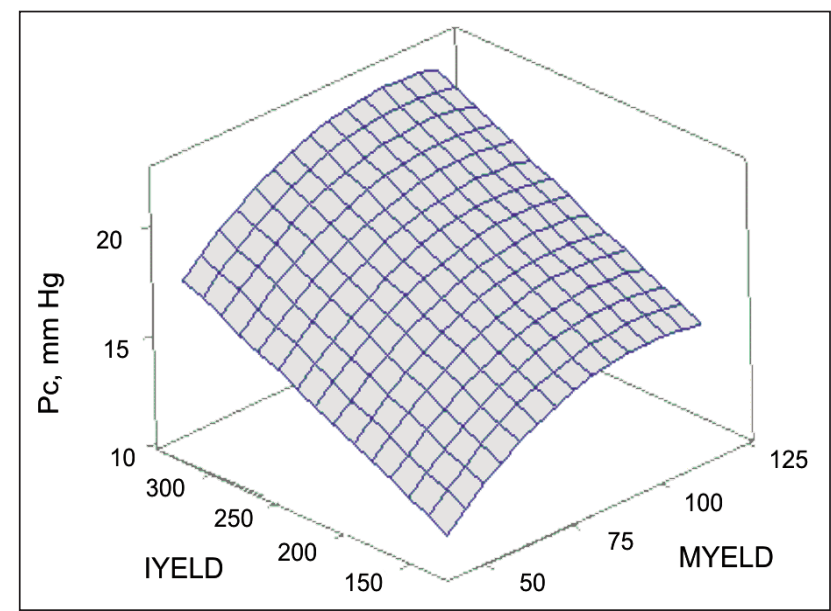

Fig. 10. Surface plot of main yarn elastane linear density (MYELD), and Inlaid yarn elastane linear density (IYELD) Vs compression pressure $(\mathrm{mm} \mathrm{Hg})$ at calf

10 and 11 show that as the linear density of the elastane material of main yarn increases from $44 \mathrm{dtex}$ to $78 \mathrm{dtex}$, the incredible increase in compression pressure from $13 \mathrm{~mm} \mathrm{Hg}$ to $17 \mathrm{~mm} \mathrm{Hg}$ takes place. As the linear density of elastane material increases more from 78 dtex to 117 dtex, a slight increase in compression pressure at the calf is observed.

Increase in compression pressure from $13 \mathrm{~mm} \mathrm{Hg}$ to $17 \mathrm{~mm} \mathrm{Hg}$ is due to increase in fabric contraction. The fabric density at calf increases as the linear density of the elastane material increases which gradually reduces loop length while increasing the stiffness and compactness of the fabric. As the linear density of the main yarn elastane material increases, there occurs a slight decrease in compression pressure. The reason of increase in compression pressure at thr calf is an increase in contraction that occurs in transverse and longitudinal directions.

In this study, we have changed the degree of needles which decreases from the calf portion (600) of the socks to ankle portion (300). The higher degree of needle causes the loose construction of the knitted fabric. This loose construction of the fabric allows it to stretch more as compared to the width of the calf. The socks prepared have the width ranged at calf from $24.13 \mathrm{~mm}$ to $26.67 \mathrm{~mm}$ (circumference $76.2 \mathrm{~mm}$ $\sim 83.82 \mathrm{~mm}$ while the wooden dummy used in this study has a circumference of $37 \mathrm{~cm}(93.98 \mathrm{~mm})$. This gradual increase in wooden dummy calf circumference shows less compatibility of the socks with the wooden leg. Consequently, due to the higher circumference of the wooden leg, extensibility of the socks and compression pressure at calf increases while increasing the size of pores.

Inlaid yarn has also a significant impact on the compression pressure at the calf. It is depicted from the figures 9,10 and 11 that as the linear density of the inlaid yarn increases from 133 dtex to 155 dtex as a significant increase in compression pressure from $13 \mathrm{~mm} \mathrm{Hg}$ to $14 \mathrm{~mm} \mathrm{Hg}$ take place. It drastically continues to increase when the linear density of the inlaid

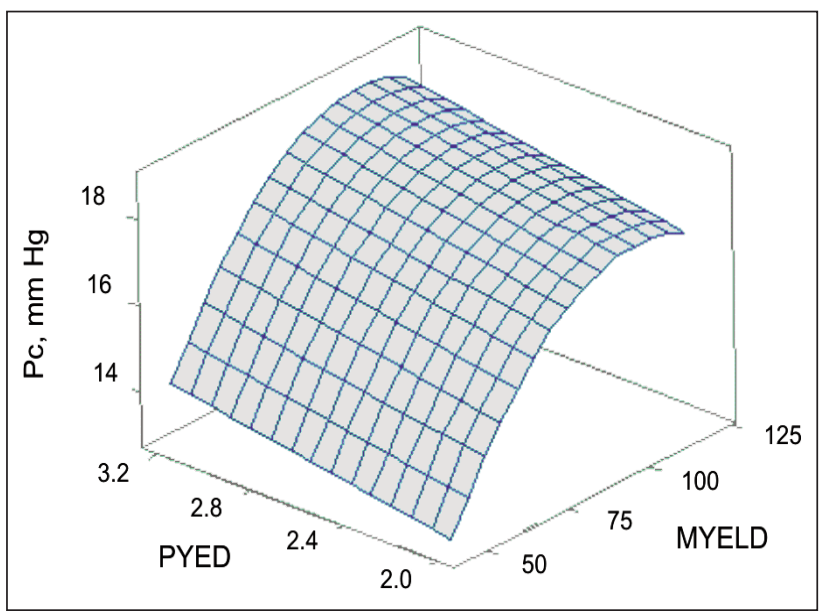

Fig. 11. Surface plot of main yarn elastane linear density (MYELD) and plating yarn elastane (PYED) draft Vs compression pressure $(\mathrm{mm} \mathrm{Hg})$ at calf

elastane yarn increases from 155 dtex to 330 dtex. Hence, the intensity of the pressure can be increased or decreased by increasing or decreasing the degree of needles and speed of the elastic motor according to requisite graduation level and to achieve the desired class of compression level.

Pressure at Calf, $\mathrm{mm} \mathrm{Hg}=-4.77+0.2734$ MYELD +

$$
\begin{gathered}
+0.03171 \text { IYELD + } 0.930 \text { PYED - } \\
-0.001336 \text { MYELD * MYELD }
\end{gathered}
$$

$\mathrm{R}$-Sq. for the regression equation (2) is $92 \%$ which indicates that $92 \%$ change in compression pressure at calf can be explained by the terms included in the equation.

\section{CONCLUSIONS}

In this study it was concluded that,

- Main yarn elastane linear density (MYELD) has significant impact on the compression pressure at the ankle. As the linear density of the main yarn elastane material increases from 44 dtex to $78 \mathrm{dtex}$ an incredible increase in compression pressure from $16 \mathrm{~mm} \mathrm{Hg}$ to $19 \mathrm{~mm} \mathrm{Hg}$ takes place at ankle. The same effect of compression pressure at calf was observed which was increased from $13 \mathrm{~mm} \mathrm{Hg}$ to $17 \mathrm{~mm} \mathrm{Hg}$ and then to $18 \mathrm{~mm} \mathrm{Hg}$ with consecutively increase of linear density of the main yarn 44 dtex to 78 dtex and then to 117 detx.

- Inlaid yarn elastane linear density (IYELD) has significant impact on the compression pressure at the ankle. As the linear density of inlaid yarn elastane material linear density increases from 133 dtex to $155 \mathrm{dtex}$ and then to $330 \mathrm{dtex}$, a significant increase in compression pressure from $15 \mathrm{~mm} \mathrm{Hg}$ to $16 \mathrm{~mm} \mathrm{Hg}$ and incredible increase to $23 \mathrm{mmHg}$ at the ankle was observed. The same significant influence of increase of linear densities of the inlaid elastane linear density from 133 dtex to 155 dtex and then to 330 dtex on compression pressure value at calf portion was observed ranging from $15 \mathrm{~mm} \mathrm{Hg}$ to $16 \mathrm{~mm} \mathrm{Hg}$ and then to $21 \mathrm{~mm} \mathrm{Hg}$. 
- Plated yarn elastane draft (PYED) has non-significant influence on the compression pressure at the ankle and calf as well. As the draft value of plating yarn elastane draft increases from 2 to 3.2 , a nonsignificant change in compression pressure at ankle from $18 \mathrm{~mm} \mathrm{Hg}$ to $18.5 \mathrm{~mm} \mathrm{Hg}$ and at calf from $16 \mathrm{~mm} \mathrm{Hg}$ to $17 \mathrm{~mm} \mathrm{Hg}$ was observed.

- Out of all newly developed V-Shape compression socks, we segregate them on the basis of graduation $\%$ values which must lies between $60 \%$ and $80 \%$. So, on the basis of this abnormality, we rejected all the socks samples that possess graduation percentage above $80 \%$ i.e. $85 \%$ to $105 \%$ which cannot be recommended for compression therapy. For this, we found only the two samples socks, M1I3P1 and M1I3P2 acquiring excellent graduation percentages i.e. $76.19 \%$ and $73.91 \%$.
- Finally, we concludedthat only two socks samples (M1I3P1 and M1I3P2) that acquire maximum compression pressure at the ankle of about $21 \mathrm{~mm} \mathrm{Hg}$ and $23 \mathrm{~mm} \mathrm{Hg}$ along with excellent graduation percentages i.e. $76.19 \%$ and $73.91 \%$. These socks samples (M1I3P1 and M1I3P2) can fulfill the compression pressure of class II as per UK, USA, and EU standards and of compression class III as per French standards.

\section{ACKNOWLEDGEMENT}

This work was supported by the Ministry of Industry and Trade of the Czech Republic, Programme Trio - project "Senior Tex - Smart Modular Clothing and Textile Products with Integrated Electronic Microsystems for Improving the Health Care of the Aging Population and Handicap People", reg. no. FV10111 as well as under the project of Student Grant Scheme SGS-18. Project reference number is 21246 .

\section{BIBLIOGRAPHY}

[1] Patrice, F., Sophie, B., Jean-Louis, C. Comparative in vitro study of three interface pressure sensors used to evaluate medical compression hosiery. In: Dermatologic Surgery, 2010, vol. 36, issue 12, pp. 1930-40.

[2] Rodica, H., Cristina, P., Cezar Doru, R. A new approach for testing medical stockings. In: Textile Research Journal, 2009, vol. 80, issue 8, pp. 683-695.

[3] Hugo, P. The use of pressure change on standing as a surrogate measure of the stiffness of a compression bandage. In: European Journal of Vascular and Endovascular Surgery, 2005, vol. pp. 415-421.

[4] Rong, L., Yi Lin, K., Yi. L., Terence T H L., Xin, Z., Xiao Qun, D. Objective evaluation of skin pressure distribution of graduated elastic compression stockings. In: Dermatologic Surgery, 2005, vol. 31, pp. 615-624.

[5] Hugo, P., Bernhard, P., Walter, B. Interface pressure and stiffness of readymade compression stockings: Comparison of in vivo and in vitro measurements. In: Journal of Vascular Surgery, 2006, vol. 44, pp. 809-814.

[6] Bera M., Chattopadhay R., and Gupta D. The effect of fibre blends on comfort characteristics of elastic knitted fabrics used for pressure garments. In: Journal of the Institution of Engineers, 2014, vol. 95, pp. 41-47.

[7] Hugo, P. Do we still need compression bandages haemo-dynamic effects of compression stockings and bandages? Sage, 2006, pp. 21:132-138.

[8] Hui, C.L., Ng, S.F. Model to predict interfacial pressures in multilayer elastic fabric tubes. In: Textile Research Journal, 2001, vol. 71, issue 8, pp. 683-687.

[9] Hui, C.L., Ng S.F. Pressure model of elastic fabric for producing pressure garments. In: Textile Research Journal, 2001, vol. 71 issue 3, pp. 275-279.

[10] Rong, L., Yi-Lin, K., Terence-T, L., Xin, Z. Effects of material properties and fabric structure characteristics of graduated compression stockings (GCS) on the skin pressure distributions. In: Fibers and Polymers, 2005, vol. 6, issue 4, pp. 322-331.

[11] Gaied, I., Drapier, S., Lun, B. Experimental assessment and analytical $2 D$ predictions of the stocking pressures induced on a model leg by Medical Compressive Stockings, In: Journal of Biomechanics, 2006, vol. 39, issue 16, pp. 3017-25.

[12] Homa, M., Marzie, A., A.H. S., Ali Asghar Asgharian, J. On the pressure behavior of tubular weft knitted fabrics constructed from textured polyester yarns. In: Journal of Engineered Fibers and Fabrics, 2011, vol. 6, issue 2.

[13] Smith, M.W.L., Dalbey, J.C. Gradient compression hosiery knitted using core spun yarns. In: USA, 7895863 B2, 2011.

[14] Olga, T., Wiah, W., Andrey, K., Chris W., Luca, O. Influence of material properties and garment composition on pressure generated by sport compression garments, In: Procedia Engineering, 2013, vol. 60, pp. 157-162.

[15] Bera, M., Chattopadhay, R., Gupta, D. The effect of fibre blend on comfort characteristics of elastic knitted fabrics used for pressure garments, In: Journal of The Institution of Engineers, 2014, vol. 95, pp: 41-47.

[16] Oğlakcioğlu, N., Sari, B., Bedez, T., Marmarali, A. A novel medical bandage with enhanced clothing comfort, In: Materials Science and Engineering, 2016, vol. 141, pp. 120-21.

[17] Rong, L., Yi-Lin, K., Yi, L., Terence, T.L. Fabric mechanical-surface properties of compression hosiery and their effects on skin pressure magnitudes when worn, In: Fibres and Textiles in Eastern Europe, 2010, vol: 18, issue. 2, pp: 91-97. 
[18] Yongrong, W., Peihua, Z., Yiping, Z. Experimental investigation the dynamic pressure attenuation of elastic fabric for compression garment, In: Textile Research Journal, 2014, vol. 84, issue 6, pp. 572-582.

[19] Capurro, S. Sheathed elastic surgical thread, USA, 10/543333,2004.

[20] Chimeh, M.Y., Latifi, M. Mojtahedi, M.R.M. Characterizing bulkiness and hairiness of air-jet textured yarn using imaging techniques. In: Journal of Textile Institute, 2005, vol. 96, pp. 251-255.

Authors:

SIDDIQUE HAFIZ FAISAL ${ }^{1}$
MAZARI ADNAN ${ }^{1}$
HAVELKA ANTONIN $^{1}$
HUSSAIN TANVEER $^{2}$

${ }^{1}$ Technical University of Liberec, Faculty of Textile Engineering Studentská 1402/2, 46117 Liberec 1, Czech Republic

${ }^{2}$ National Textile University, Textile Engineering Sheikhupura Road, Manawala 37610, Faisalabad, Pakistan

e-mail: faisalsiddique3648@gmail.com, adnanmazari86@gmail.com, antonin.havelka@tul.cz, mehr_azam91@yahoo.com, hussain.tanveer@gmail.com

Corresponding author:

SIDDIQUE HAFIZ FAISAL

e-mail: faisalsiddique3648@gmail.com 